\title{
A alteridade como critério para cuidar e educar nutrizes: reflexões filosóficas da prática
}

\author{
The alterity as a criterion to care and to educate mothers who breastfeed: philosophical reflections of practice \\ La alteridad cómo criterio para cuidar y educar las madres que amamantan: refexiones filosoficas de la práctica
}

\author{
Maria de Lourdes Campos Hames', Telma Elisa Carraro', \\ Flávia Regina Ramos', Adriana Dutra Tholl"I \\ 'Universidade Federal de Santa Catarina, Departamento de Enfermagem, \\ Grupo de Pesquisa Cuidando e Confortando. Florianópolis, SP \\ "Universidade do Vale do Itajaí. Itajaí, SC
}

Submissão: $11 / 05 / 2006$

Aprovação: 23/05/2007

\section{RESUMO}

Este estudo configura-se como um ensaio teórico-filosófico da prática do cuidar-educar nutrizes, embasada no nosso cotidiano profissional e no conceito de alteridade desenvolvido por Emmanuel Lévinas. Traz à tona as inquietudes Que povoam nossos pensamentos na busca de um algo a mais no sentido do estabelecimento de um agir mutuamente comprometido no cuidar de mulheres Que experenciam o processo de amamentação. Acreditamos que a alteridade é um critério ético fundamental Que ao ser removido das relações de cuidado, o diálogo não se estabelece e o cuidado pode não se efetivar, porQue o pensamento dominante da normalidade, acaba por anular o ser nutriz, estabelecendo, a priori, a forma de pensar e viver a situação.

Descritores: Aleitamento materno; Comportamento materno; Autonomia pessoal.

\section{ABSTRACT}

This study is configured as a philosophical-theorical essay about the practice of teaching and educating mothers who are breastfeeding and is based on our professional daily activity and on the concept of alterity developed by Emmanuel Levinas. It broughts to light the disturbance that fill our minds in the search for something bigger in the sense of establishing a mutual obligation in the caring of women that experience the nursing process. We belive that alterity is a fundamental ethical criterion that when removed from care relations disturbs the dialogue and caring may not be effective, because the dominant thinking of normality eliminates the nursing-mother being, establishing a priori, the thinking manner to live a given situation.

Descriptors: Breast feeding; Maternal behavior; personal autonomy.

\section{RESUMEN}

El presente estudio se un ensayo teórico-filosófico acerca de la práctica del cuidar-educar nutrízes; teniendo como base el cotidiano profesional y el concepto de la alteridad desarrollado por Emmanuel Lévinas. Donde muestran las inquietudes Que habitan en nuestros pensamientos frente a la búsqueda siempre de "algo más", en el sentido de establecer una actuación comprometida mutuamente en el cuidar de las mujeres Que viven la experiencia del proceso de amamantamiento. Creemos, Que la diferencia es uno de los criterios éticos fundamentales el cual, al ser apartado de las relaciones del cuidado, el diálogo no se establece y consecuentemente, el cuidado podría no ser efectivo; por Que el pensamiento dominante de la normalidad, termina anulando el ser nutriz.

Descriptores: Lactancia materna; Conducta materna; autonomía personal. 


\section{INTRODUÇÃO}

Apesar do maravilhoso desenvolvimento técnico-científico do mundo no decorrer do último século, chegamos ao novo milênio ainda inseguros Quanto a nossa prática cotidiana de enfermeiros Que buscam no saber a compreensão das Questões Que envolvem a complexidade do existir humano e do ser profissional que cuida e educa pessoas para, sem e com saúde.

Refletindo sobre a ciência na atualidade percebemos que o necessário progresso científico Que nos garante a sobrevida biológica diante das situações mais críticas, pode, em determinadas situações, retirar-nos o que nos diferencia eneuanto humanidade: - a condição de sapiens sapiens, ou seja, de seres Que sabem e sabem que sabem ${ }^{(1)}$, distituindo-nos da individualidade e do subjetivismo. Enquanto profissionais da saúde e pessoas acreditamos Que viver somente sob o prisma da racionalidade sistêmica contemporânea é correr o risco de desconstruir nossas identidades e, conseqüentemente, daqueles que cuidamos. Na relação de cuidado há necessidade de mais- todos sabemos.

$\mathrm{Na}$ busca deste algo a mais viemos, ao longo dos últimos anos de atuação docente-assistencial na área da saúde, empreendendo esforços no sentido de estabelecer um agir mutuamente comprometido e o mais próximo possível da realidade das mulheres Que experenciam este processo.

Apesar dos esforços no sentido do desenvolvimento de uma ação profissional efetivamente comprometida para o cuidar-educar nutrizes na última década, ainda percebemos a existência de uma verdade absoluta para a Questão - único risco a ser percorrido pela diversidade de vidas Que o vivenciam. O reducionismo científico desta unicidade acaba, arbitrariamente, aprisionando a mulher em sua própria história, condicionando-lhe o pensamento e a certeza da imutabilidade da sua condição de nutriz e de pessoa, removendoIhe o caráter subjetivo, como a desconsiderar a sua concretude histórico-sócio-política eternamente inconclusa. Sobre esta arbitrariedade, manifestamos o nosso inconformismo - origem de nossas inquietudes.

Dentre as muitas inquietudes Que povoam nossos pensamentos, o Que presentemente mais nos assusta é a constatação da perda da capacidade profissional para o ouvir, o ver (para além do sentido da visão), o colocar-se a disposição do Outro nutriz. Ficamos perplexas diante da constatação da inabilidade em compreendermos Que a pluralidade destas mulheres é Que determinará as suas singularidades. Somos constituídos na diferença e a permanência da diferença é a garantia da alteridade ${ }^{(2)}$.

$\mathrm{Na}$ busca da compreensão do Que se coloca imperioso na face nutriz Que silenciosamente grita em nossas relações de cuidareducar para a amamentação e, compreendendo a complexidade dinâmica Que envolve o processo nos nossos dias, ousamos escrever nossas reflexões, utilizando-nos de um conceito antigo, porém esquecido numa sociedade contemporânea de primazia do Eu, a alteridade, sobre o eual passamos a descrever na segunda etapa deste ensaio teórico. Cabe ressaltar Que tal abordagem terá como referência, as idéias do filósofo judeu Emmanuel Lévinas em suas diversas obras.

Pensar a alteridade como critério ético fundamental e aplicá-lo às situações de saúde, vêm ao encontro das exigências atuais de se atribuir aos indivíduos cuidados a competência moral e seu posicionamento como sujeitos deste cuidado, portanto, conscientes de si e com visão critica do sistema de saúde. Por outro lado, também os profissionais envolvidos serão chamados a esta ação. Afirma-se "a inclusão da alteridade como critério ético confirma os valores humanos como referência para os comportamentos profissionais" ${ }^{\text {(3). }}$.

Apresentando nossas reflexões filosoficamente fundamentadas, tentamos contribuir para a estruturação de uma nova maneira de cuidar - Que não é única e nem exclusividade nossa, mas que, com certeza, facilitará o resgate da essência do nosso ser profissional comprometido com a história da profissão e da humanidade deste cuidar. Humanidade tantas vezes negada, pouca vezes dadas e raramente compartilhada nas relações cuidador-pessoa a ser cuidada.

Precisamos pensar o nosso ser profissional e nutriz, pensar aQui entendido como um des-velamento Que tanto procura explicitar aQuilo Que nele permanece como impensável, como ultrapassar o sistema dominante de reflexão em Que se insere ${ }^{(4)}$. Isto porque "a liberdade consiste em saber Que a liberdade está em perigo"(2). Ao sujeito que se define pelo cuidado de si, coloca o desejo do Outro - do Qual o Eu não é complemento, porQue este Outro se encontra além daquilo Que lhe possa faltar ou satisfazer ${ }^{(2)}$.

A relação de cuidado com alteridade nos permitirá superar a visão abstrata e individualista do personalismo, resgatando o sujeito real e concreto para a ética, permitindo-lhe viver para além da mediação política. Afinal, re-significar o cuidar no contexto desigual da assistência à saúde dos nossos dias, reQuer uma apurada revisão dos preceitos humanísticos Que constituem este agir, no sentido de possibilitar aos envolvidos (cuidador-pessoa a ser cuidada), o desenvolvimento de uma consciência crítica numa práxis libertadorao estabelecimento de uma relação dialógica onde ambos se contemplam e são contemplados.

\section{SOBRE O CONCEITO DE ALTERIDADE: ETIMOLOGIA E ABORDAGENS HISTÓRICAS}

$\mathrm{Na}$ tentativa de facilitar a compreensão das reflexões Que se seguem passamos a abordar, de forma sucinta, o termo alteridade e sua etimologia, perpassando pelas diversas abordagens filosóficas do conceito ao longo da história. Pois bem, o termo alteridade deriva da palavra latina alteritas (outro). O seu conceito como utilizamos hoje, substantivado, tem sua origem grega e significa diferença, diversidade. De uma forma ontológica compreende a condição de um ser distinto de outro no seu modo de ser específico ou no seu fato de ser numérico, isto é, na sua essência ou na sua existência: contrapõe-se a identidade de um ser consigo mesmo. A operação intelectual pela eual distinguimos a alteridade é denominada distinção e sua existência efetiva traduz-se pelo conceito de diversidade $\mathrm{e}^{(5)}$.

$\mathrm{Na}$ idade moderna e contemporânea aparece nos escritos de Hegel, exprimindo-se ao nível da consciência como a afirmação da "relação categorial entre algo e seu outro do finito, enquanto limitação mútua Que constitui a dinâmica da dialética do ser-em-si ou ser-para-si, como movimento completo Que se encerra a si mesmo, ou seja, "a transformação de um ser no seu ser, sem, contudo, anular o algo Que estava destinado a alterar-se"(5). Utilizouse este conceito para a definição da natureza com relação a idéia, Que considera a totalidade racional da realidade, ou seja: "A natureza 
é a idéia na forma de ser Outro. Desse modo é a negação de si mesma e é exterior a si mesma, de modo que a exterioridade constitui a determinação fundamental da natureza. Mas, de modo geral, podese dizer Que, segundo Hegel, a alteridade acompanha todo o desenvolvimento dialético da idéia, porque é inerente ao momento negativo, intrínseco a esse desenvolvimento. De fato, tão logo estejam fora do ser indeterminado, Que tem como negação o nada puro, as determinações negativas da idéia tornam-se, por sua vez, alguma coisa de determinado, isto é, um ser outro, Que não aQuilo mesmo Que negam. A negação não mais como um nada abstrato, mas como um ser determinado e um algo- é somente forma para esse algo, é um ser outro"(6).

Por sua vez, Feuerbach acreditava Que a alteridade só era possível "através do conceito, dos sentidos, do corpo, do homem na natureza, de uma relação entre Eu e Tu, pois a relação a si não poderia acontecer senão na relação no outro" ${ }^{(6)}$. A sua originalidade centrava-se no pensar a religião como a relação do homem a sua essência, "a um ser particular dele distinto, transcendente". Renouvier (Logique) trata a alteridade como fundamento à categoria de relação, Que sempre pressupõe diferença percebida em três momentos: o de ipsiedade,

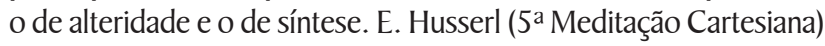
fala de uma "inter-relação entre o Eu e um Alter-Ego determinando a própria subjetividade do Eu puro no seu núcleo"(6).

A constituição fenomenológica do sujeito Husserliano levou alguns pensadores judeus, como Martin Buber e Emmanuel Lévinas, a repensarem a alteridade numa visão ético-ontológica. Buber defende a idéia Que no face-a-face as pessoas se confirmam pelo Outro por meio da múltipla responsabilidade. Desta forma, o "Euisto- coisificante e substantivado pelo princípio do Eu-Tu, copresença não mediatizada"(6).

\section{A ALTERIDADE EM EMMANUEL LÉVINAS: IMPLICAÇÕES E DESDOBRAMENTOS}

Como mencionado anteriormente, para a elaboração destas reflexões baseamo-nos, principalmente, nas idéias do filósofo Emmanuel Lévinas relativas a alteridade, sobre as Quais passamos a discorrer.

"A alteridade é um esforço de restituição de cidadania e primazia ontológica ao Outro, negada no conjunto da história da filosofia ocidental”(5). Ora, a presença do Outro num face a face originário me faz repensar os privilégios de Eu; insinua-se simultaneamente no pensamento do Outro com a mesma exigência ética, fazendo surgir a alteridade absoluta a partir de uma exterioridade Que "não se deixa derivar, nem engendrar, nem constituir a partir de uma outra instância se não ela mesma”"(6). Desta forma, podemos dizer Que este conceito coloca-se maior que a identidade e menor que a cidadania, pois a identidade, enQuanto movimento interior do ser, revela-se no desejo de ser idem, de resgatar a sua identificação ao contexto e tornar-se universal (mais um). Por outro lado, a identidade exterior o torna alter, distinto, diferente, ser único - um Outro constituído.

O autor desenvolveu este conceito na vivência como judeu ao horror nazista dos campos de concentração, situação em Que percebia o outro negado em sua alteridade e afirmado em sua diferença em face do sentido dado pelo projeto alemão.

Ao ser vigiado pela janela por soldados alemãs, após voltar das longas jornadas de trabalho forçado, reconheceu a inexistência da alteridade na situação, concluindo Que "o existente Que dá sentido aos entes no mundo, estaria numa impessoalidade, árida, neutra, Que somente poderia ser superarda no ser-para-o-outro, como momento ético de respeito a alteridade"(7). "A relação entre o Mesmo com o Outro, nem sempre se reduz ao conhecimento do Outro pelo Mesmo, nem seQuer à revelação do Outro ao Mesmo"(2), porque este Outro constituído já seria fundamentalmente diferente do desvelamento.

Na relação com o Outro, cria-se a consciência moral dos sujeitos. O Outro é então, o meu limite, impedindo-me de prosseguir a invadi-lo. A relação do Mesmo com o Outro se dá pela linguagem. "Falar supõe uma possibilidade de romper e de começar" (2), pois o desejo da exterioridade que transcende o ser, move-se no discurso e não no conhecimento.

"A consciência ética jamais pode prescindir do encontro da voz Que interpela, a partir da sua exterioridade, com aquele que a escuta"(8). E a alteridade se constitui neste espaço. Espaço Que ouso chamar de dialógico, porque o Outro diferente me interpela a novas condutas e atitudes frente ao vivenciado.

No mundo globalizado, marcado pela individualidade e pela concepção de uma ética hedonista, a traneüilidade consciente das pessoas indiferentes aos rostos Que ameaçam se expor, está fadada ao fracasso. Uma saída, mesmo Que não a única, constitui-se na ética da alteridade, encuanto possibilidade do resgate da sensibilidade para o acolhimento do Outro, responsabilidade dual infinita dos sujeitos envolvidos no face a face, resgate do humanismo.

\section{CUIDAR-EDUCAR COM ALTERIDADE PARA O PROCESSO DE AMAMENTAÇÃO: UMA POSSIBILIDADE DE PRÁTICA COMPROMETIDA}

O esgotamento do modelo promotor e culpabilista do aleitamento materno, constatado pela estagnação dos índices de amamentação exclusiva nos últimos anos em nossa sociedade, nos levam a Questionar as formas ideológicas de desconstrução e reconstrução social desta prática, híbrida de valores ${ }^{(9)}$. O interesse mercadológico, a Questão do gênero, a aparente incapacidade epistemológica profissional de responder a alteridade das mulheres nutrizes em seus distintos contextos de vida ao longo da história, a constatação da descrença no processo, entre outros fatores, nos impelem à necessária procura do estabelecimento de uma nova relação profissional para este cuidar-educar, uma relação regida pela ética e pela responsabilidade.

Trata-se de devolver a alteridade Que nos foi negada (enquanto mulheres) pelo estranhamento do ato considerado primitivo pelos civilizados povos europeus e livrar-nos da violência Que provocou o extermínio desta prática incorporada na sociedade indígena brasileira de antes do descobrimento ${ }^{(9)}$. Trata-se da necessidade de construção de um novo horizonte na prática profissional Que considere a diferença não como uma concorrência ou ameaça, mas como uma rieueza Que, ao ser compartilhada, promoverá um mútuo crescimento.

Ao falarem da necessidade de resgatarmos a diferença na cultura ocidental, mencionam Que precisamos retomar o movimento de olhar no espelho de nossas próprias faces civilizacionais (afinal, a alteridade parte sempre de Mim) e, constantemente, nos 
Questionarmos sobre nossas práticas e saberes ${ }^{(10)}$. Citam Que, uma das provas de nossa insegurança civilizacional, são os modelos de conceptualização e legitimação das diferenças, construídos ao longo da história, como o etnocêntrico, o da tolerância, o da generosidade e o relacional. Com certeza, este último modelo citado é o que mais se aproxima da possibilidade do estabelecimento de uma relação de alteridade, pois, ao reconhecer o Outro diferente, também a si se reconhece como diferente; e esta relação de diferentes recusa uma ação unilateral. Desta forma, somos impelidos a expor nossa alteridade no contexto, tornamo-nos mais frágeis para permitir o surgimento do Outro.

Para o estabelecimento desta nova relação precisamos respeitar a nutriz como dona de sua vida, ser único, livre, autônomo; precisamos nos despir da supremacia do saber profissional e, sem manter a mulher na ignorância, deixar aberto o espaço ao diálogo com sensibilidade e reflexão. No face a face com o outro criamos nossa consciência moral, uma relação de alteridade, porque o profissional sai de si mesmo pelo chamamento do Outro Que surge diferente, comprometido com a sua saúde e exigindo deste profissional um preparo mais adequado e mais autêntico. Nesta autenticidade, os critérios da beneficência, da autonomia e da justiça não podem ser negados. Estabelece-se uma relação simétrica no sentido do vir-a-ser destes sujeitos, Que se contemplam como capazes e únicos.

Precisamos, enQuanto profissionais, pensar que a alteridade do sistema de cuidado à mulher em vivência do processo de amamentação, pode destruir a alteridade do Outro nutriz, marca da sua diferença. Isto porque esta totalidade é fechada, limitando-se sempre a ouvir, a interpretar aquela Que fala sobre o Mesmo. Desta forma, destrói o diálogo, desenha um monólogo. Este "monólogo é tautológico, mesmo Que seja entre dois homens diferentes, internos à totalidade e, a voz da totalidade é a voz do uno, mera reafirmação da totalidade sem novidade"(8). Basta pensarmos Que a existência de um modelo comportamental no cuidado Que define o comportamento esperado das pessoas envolvidas (cuidador-ser cuidado), "inibe a criatividade, o pensamento independente e crítico, a individuação, a capacidade de visualizar o todo e de encontrar significações nas ações profissionais e pessoais"(11).

Devemos acreditar Que esta mulher é capaz de estabelecer o seu bem na situação, a partir de sua própria perspectiva. Desta forma " o poder do Eu percorrerá a distância indicada pela alteridade do Outro"(II); assim sendo, a justiça, a beneficência e a autonomia, princípios básicos da bioética serão preservados, abrindo-se novos horizontes na relação nutriz-profissional com construção de conhecimento eficaz e centrado na realidade individual - um agir comprometido. Afinal, este agir não se limita a uma execução de ordens prescritas, é refletido a priori, é pensado, estando o profissional diretamente envolvido desta condução. O entendimento de como o amamentar se processa na percepção da nutriz, única e exclusiva na sua história de vida, é um caminho epistemológico para tornar mais eficiente o agir profissional(12).

Pensando a prática cotidiana, Quantas vezes nos vemos diante de situações de cuidado Que, de antemão, já percebemos ineficazes. Mas calamos e abandonamos esta nutriz ao infortúnio gerado pelo modelo regulador da conduta moral na situação. Modelo Que construímos, enquanto profissionais e nutrizes e do Qual a nos tornamos vítimas. Quantas vezes percebemos estas mulheres violentadas pelo nosso cômodo silêncio.

Mas o silêncio diante do que é considerado incorreto pelo profissional incomoda e é uma omissão expressa à pessoa Que cuidamos, ferindo os seus direitos e descaracterizando a visão de Que esta deve estar integrada e ser participante ativa do seu próprio cuidado $^{(13)}$. É, portanto, uma negação da sua alteridade.

O cuidado é um processo, portanto, só pode se dar de forma interativa entre o cuidador e a pessoa a ser cuidada ${ }^{(1)}$. A relação de cuidado será estabelecida se certas condições como a disponibilidade, a receptividade, a intencionalidade, a confiança, o conhecimento, entre outras, se fizerem presentes. Desta forma, estar com o ser Que será cuidado (para além do corpo físico), permite o envolvimento deste na relação, facilitando a expressão da consciência, do afeto e da subjetividade- condição essencial para a expressão da alteridade dos sujeitos envolvidos.

Ao removermos a alteridade das relações de cuidado (aqui especificamente o educar cuidar de mulheres Que amamentam seus filhos) o diálogo não se estabelece, o cuidado não se efetiva, porQue o pensamento dominante para o processo, a normalidade, acaba por anular o ser nutriz. O normal torna-se normativo na relação de cuidado, estabelecendo, a priori, a forma de pensar e viver a situação.

A despersonalização do ser nutriz parte de um juízo científico considerado verdade una, fixa e incapaz de permitir a transparência dos seres na relação de proximidade. EnQuanto rostos Que não fazem parte deste contexto, não são nem diferentes e nem iguais, pois se de tal forma se comportassem já seriam parte de uma totalidade- e não um Outro constituído. Isto acaba por desconstruir a epistemologia pessoal do processo e , em lugar desta, coloca-se a semelhança e a pertença como a chance de sobreviver ileso na estrutura desenhada por todos e para todos.

Precisamos resgatar o ouvir como imperativo ético nas relações de cuidado. " O mundo silencioso é um mundo que nos vem de Outrem. O silêncio não é assim, uma simples ausência de palavras; a palavra está no fundo do silêncio"(2).

Não é mais possível estar e falar num face a face com a mulher nutriz in-consciente da condição de submissão Que estamos submetidos (e aqui incluo a cegueira profissional para o modelo normalizador da conduta nutriz). Só Que o necessário rompimento requer, a priori, algo que precede a nossa intencionalidade - o desejo, a necessidade. Quando começarmos o reconhecimento da mulher Que amamenta, para além da totalidade nutriz, começaremos a desenvolver uma prática educativa libertadora, pois, " se o Mesmo se identificasse por simples oposição ao Outro, faria já parte de uma totalidade englobando o Mesmo e o Outro"(2). E não seria um Outro nutriz, mas o Mesmo adaptado. A alteridade nutriz não se desenha fora do contexto de cuidar-educar mulheres em vivência do processo de amamentação, mas cerceada por linhas invisíveis dentro deste mesmo contexto, manipulável, Que nega e se refugia no negado para manter os contornos do Mesmo e do Eu.

\section{REFLEXÕES FINAIS}

O exercício diário do ser enfermeira ultrapassa, em muito, a competência técnica do cuidado corporal, independente da área de atuação Que estejamos envolvidas. Especificamente sobre problemática cuidar-educar para o amamentar, alvo destas reflexões, precisamos considerar Que o processo é multidimensional e começa 
numa Questão anterior... Questão Que envolve uma concretude sócio-histórico-cultural da Qual, na maioria das vezes, pouco conhecemos $^{(14)}$. A compreensão da necessidade deste aprofundamento e o agir no sentido deste devir, nos conduzirá à descoberta da dimensão esQuecida do cuidado objetivado e alienado, a subjetividade, o eu escondido pela alteridade negada.

Não se trata apenas de permitir a expressão dos prós e contras em relação ao processo, mas ir além disto- mostrar a face oculta dos sujeitos nesta relação de proximidade. Permitir a transcendência, o infinito descrito por Lévinas ${ }^{(2)}$. Uma face Que não é só da nutriz, mas também minha enQuanto profissional. Precisamos pensar o novo Que se institui pelo relacionamento alter, como uma possibilidade de percebermos, para além da superficialidade, o nosso ser enfermeira; possibilidade ainda, de Questionarmos nossas atitudes e construirmos uma nova alternativa para um agir comprometido e eficaz. Afinal, a alteridade total do ser não transparece na forma das coisas pela Qual elas se abrem a nós, porque sob a forma, as coisas se escondem ${ }^{(2)}$.

A resistência do Outro nutriz Que fala ou Que cala, Que exibe uma face Que sofre ou Que sente prazer, encobre outra face marcada pela diversidade e desconhecida.E este ser nutriz me ouve, me olha e pensa o Que não sei ${ }^{(15)}$.

O regresso ao ser unívoco a partir do mundo dos signos e dos símbolos da existência fenomenal não consiste em integrar-se todo tal como a inteligência o concebe e tal como a política o instaura. A independência do ser separado encontra-se aí perdida, menosprezada e oprimida. O regresso ao seu exterior, ao ser em sentido unívoco- sentido Que não esconde nenhum outro- é entrar na retidão do frente a frente. Não é um jogo de espelhos, mas a minha responsabilidade, ou seja, a existência já empenhada ${ }^{(2)}$.

Para o desenvolvimento de uma práxis libertadora para o cuidareducar mulheres em processo de amamentação, precisamos deixar de lado a totalidade englobante que nos impede de ouvi-la e vê-la, sufocada numa cultura em Que o Nós é visto como o Eu, modelo de uma práxis dominadora e excludente. Precisamos abandonar certos princípios morais, impetrando em seu lócus, uma consciência ética.

Somos responsáveis pelo que construímos. Precisamos permitir a transparência dos rostos Que se colocam diante de nós enQuanto alternativa de construção de um novo modelo de atenção à saúde cuja prática se dê numa relação de horizontalidade e onde ambos, cuidador e ser cuidado, precisam desistir de algo para Que o cuidado ético se estabeleça.

Se, por um lado, a mulher nutriz precisa despir-se da sua posição de mera receptora de cuidado e fazer valer a sua autonomia, por outro, o profissional de saúde precisa despir-se da sua condição de autoridade suprema (mesmo Que mascarada na forma do princípio da beneficência), para Que a alteridade emirja no contexto relacional. Isto porQue o ateísmo do Eu marca, sem dúvida, a ruptura da participação e, conseQüentemente, a possibilidade de se procurar uma justificação, ou seja, uma dependência em relação a uma exterioridade sem Que tal dependência absorva o ser dependente, mantido dentro de redes invisíveis. Dependência, por conseguinte, Que, ao mesmo tempo, mantém a independência. Tal é a relação do frente a frente ${ }^{(2)}$.

A liberdade, determinação do Outro nutriz pelo Mesmo, seria "o próprio nascimento da representação e da sua independência"(2). Liberdade eneuanto arQuétipo fundador; independência eneuanto exercício pleno da autonomia e humanismo. Descentrados ouviremos a voz do outro, reconheceremos seu rosto e seremos pelo mesmo reconhecidos. Estabeleceremos uma relação de autenticidade, um cuidado efetivo.

$\mathrm{Na}$ interação com a nutriz, a possibilidade de troca se faz a cada instante, resgatando o prazer profissional de renovar-se e estar com a mesma no continuo vir-a-ser. A grande beleza do nosso trabalho é que ele, a cada segundo, se faz diferente.

\section{REFERÊNCIAS}

I. Chaui M. A política contra a servidão voluntária. In: Chaui M. Convite a filosofia moderna Chauí. $12^{\text {a }}$ ed. São Paulo (SP): Ática; 2000. p. 407-22.

2. Lévinas E. Totalidade e infinito. Lisboa (POR): Edições 70; 2000.

3. Sadala MLA. A alteridade: o outro como critério. Rev Esc Enferm USP 1999; 33(4): 355-7.

4. França C, Dias S. Manifesto do partido comparativista . In: Costa CCS. Blue \& brown notebooks. Lisboa (POR): Editora Fenda; 2001 .

5. Boudon R, Bourricaud F. Dicionario crítico de sociologia. São Paulo (SP): Ática; 1993

6. Abbagnano N. Dicionário de filosofia. $2^{\text {a }}$ ed. São Paulo (SP): Martins Fontes; 1998.

7. Mance EA. Emmanuel Lévinas e a alteridade. Rev Filos 1994; 7(8): 23-30.

8. Silva MB. Rosto e alteridade: pressupostos da ética comunitária. São Paulo (SP): Paulus; 1995.
9. Almeida |AG. Amamentação: um híbrido natureza-cultura. Rio de laneiro (RJ): Fiocruz; 1999.

10. Magalhães AM, Stoer SR. A diferença somos nós. J Pag Educ 2003; 12(12I): 7 .

II. Waldow VR. Cogitando sobre o cuidado humano. Cogitare Enferm 1998; 3(2): 7- 10.

12. Rezende MA, Sigaud CHS, Veríssimo MLOR, Chiesa AM, Bertolozzi MR. O processo de comunicação na promoção do aleitamento materno. Rev Latino-am Enfermagem 2002; 10(2): 234-8.

13. Selli L. Bioética na enfermagem. São Leopoldo (RS): Editora da UNISINOS; 1998.

14. Hames MLC. Amamentação: conflito e harmonia no espaço interativo enfermeira, puérpera e sua família. Florianópolis (SC) [dissertação]. Florianópolis (SC): Programa de PósGraduação em Enfermagem, Universidade Federal de Santa Catarina; 2001.

15. Gambini R. Uma breve reflexão sobre o outro. Rev Psicol USP 1 994: 5(1/2):335-9. 